\title{
Physical Characterization of Palm Fatty Acid Distillate (PFAD) Blends as Biofuel
}

\author{
Mantari M.H.A.R ${ }^{11}$, Hassim H.M ${ }^{1}$, Rahman R.A ${ }^{1}$, Zin A.F.M ${ }^{1}$, Mohamad M.A.H ${ }^{1}$, \\ Asmuin. $\mathrm{N}^{2}$ \\ ${ }^{1}$ Department of Mechanical Engineering, Centre for Diploma Studies, Universiti Tun Hussein Onn \\ Malaysia \\ ${ }^{2}$ Department of Energy and Thermofluid, Faculty of Mechanical and Manufacturing, Universiti Tun \\ Hussein Onn Malaysia
}

\begin{abstract}
Palm oil has been accepted to be used as fuel with the introduction of petroleum diesel and Palm Methyl Ester (PME) in 2014. The high cost is the major drawback of PME. Not only PME is derived from an expensive low Free Fatty Acid (FFA) feedstock, the cost to convert FFA to PME through the process of trans esterification and purification of palm oil fatty acid is also expensive. Alternative feedstock of FFA is palm fatty acid distillate (PFAD). PFAD is a by-product of crude palm oil (CPO) refining. It is inedible and a low price palm oil product making it attractive as a feedstock for biofuel. The high viscosity of PFAD can be reduced by blending it with diesel fuel. Five blends of PFAD and diesel blends with $2 \%, 4 \%, 6 \%, 8 \%$ and $10 \%$ volumetric ratio were produced in this study. The physical properties of the blends such as density, viscosity, surface tension and flash point were determined and the results were compared to the Malaysian Standard for Diesel Fuel (MS123:2014). The results show that all properties of the blends are within the acceptable value for diesel fuel.
\end{abstract}

\section{Introduction}

Oil palm is one of the cash crops that is widely planted in Malaysia and Indonesia. Palm oil industry is a significant contributor to Malaysian economy providing both employment and income from exports. The history of palm oil as fuel started in the 1980s by Malaysia Palm Oil Board (MPOB) with their in house trial using a diesel engine and fully commercialized by government directive in 2014 as B5 that constitute a blend of $95 \%$ petroleum diesel and $5 \%$ palm methyl ester (Hamim, 2014). The palm methyl ester is produced from transesterification and purification of palm oil fatty acid and reacted with alcohol to produce palm methyl ester and glycerol (Krisnangkura, 1992).

\footnotetext{
*Corresponding author: mhanafi@uthm.edu.my
} 
The main drawback of palm oil biodiesel is the high production cost. The high cost of producing the biodiesel product is due to its feedstock which come from high quality of virgin oil with low free fatty acid (FFA) contents (Chongkhong, 2008). In order to overcome this limitation, the biodiesel product needs to be produced by using cheaper feedstock either recycled or waste oils, or by product of refining vegetable oil that contains high FFA.

Source of feedstock that can be an alternative in producing the fuel from oil palm is by using palm fatty acid distillate (PFAD). The PFAD is a by-product of crude palm oil $(\mathrm{CPO})$ refining. PFAD is inedible and low price palm oil product making it attractive as a feedstock for biofuel. PFAD contain high free fatty acid (FFA) that account up to $70 \%-80 \%$ and the remaining is triglyceride (Ping, 1992). The high content FFA requires two step operations that are esterification and trans-esterification reactions in order to convert it to become methyl ester (Chongkhong, 2007). Another method to utilize PFAD as a biofuel source is to direct blend it with petroleum diesel. This process eliminates the needs of the costly esterification and trans-esterification operation.

The use of a direct blend of palm oil product had already been done by several researchers. The blends of Refine, Bleach and Deodorized Palm Olein (RBDPO) with petroleum diesel gave a comparable performance to petroleum diesel in terms of spray and combustion characteristics especially at lower blend (10\% blend) (Mantari, 2009).

The availability of PFAD as a low cost, non-food source feedstock is significant thus provide opportunity for biodiesel producers with excellent access to a low-cost, non-food source of feedstock (Cheah, 2010). The PFAD in comparison with other products of palm oil such as Refine Bleached Deodorized (RBD) Palm Oil, RBD Palm Olein and RBD Palm Stearin is always being traded at the lowest price as shown in Figure 1. Before the year 2012, the PFADs were traded at the discounted price that exceeds RM 500/MT and increases in the year 2011 with the discount exceeds RM700/MT. However, the gap between the prices was narrow from year of 2013, 2014 and 2015. The range of palm oil product's price for seven years are in between of $-27 \%$ to $18 \%$.

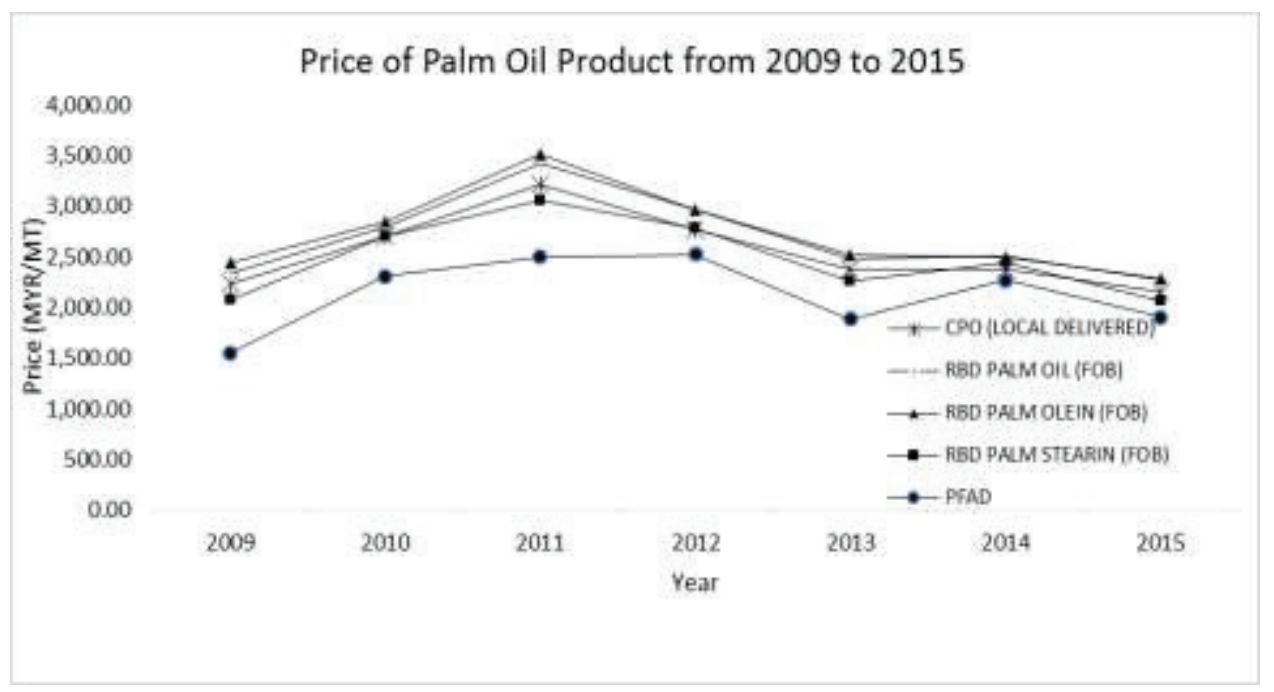

Fig. 1. Price comparison of PFAD with Others Palm Oil RPB product (MPOB, 2015) 


\section{Methodology}

The quantity of each element in PFAD-diesel blend depends on its mixing ratio for instance if B2, then it contains $98 \%$ of petroleum diesel and $2 \%$ PFAD. The rest of the blends and their volumetric ratio are shown in Table 2.1. A total 5 litres of PFAD-diesel blend was produced according to the designated blending ratio. The blending was done using magnetic stirrer at temperature $50^{\circ} \mathrm{C}$ and was stirred for 15 minutes to allow the mixture to be homogenous.

Table 2.1. Composition of PFAD and Diesel for Each Blend

\begin{tabular}{|c|c|c|c|c|}
\hline Blends & $\begin{array}{c}\text { Percentage of PFAD contain in } \\
\text { the blend }\end{array}$ & PFAD (litre) & Diesel (litre) & Total (litre) \\
\hline B0 & $0 \%$ & 0 & 5 & 5 \\
B2 & $2 \%$ & 0.1 & 4.9 & 5 \\
B4 & $4 \%$ & 0.2 & 4.8 & 5 \\
B6 & $6 \%$ & 0.3 & 4.7 & 5 \\
B8 & $8 \%$ & 0.4 & 4.6 & 5 \\
B10 & $10 \%$ & 0.5 & 4.5 & 5 \\
\hline
\end{tabular}

The measurement of the physical properties was conducted according to the guideline prepared by world renowned standard bodies such as American Society and Testing Material (ASTM) and International Organization for Standardization (ISO). The density measurement was done according to ASTM D 4052 while for kinematics viscosity, the test was done according to ISO 3104. The surface tensions of these samples were measured according to ASTM D971. The flash points for these samples were tested according to Pensky-Martens closed cup (PMCC) as detailed in ISO 2719.

\section{Results and Discussion}

The physical characteristics of Palm Fatty Acid Distillate (PFAD) blend with diesel were investigated. The physical characteristics that have been tested include the dynamic viscosity and kinematic viscosity at $40{ }^{\circ} \mathrm{C}$, surface tension at $27{ }^{\circ} \mathrm{C}$ and flash point of PFAD. The Malaysia MS-123-1:2014 have been chosen as the benchmark for comparison of the physical characteristics of diesel and PFAD blend. 


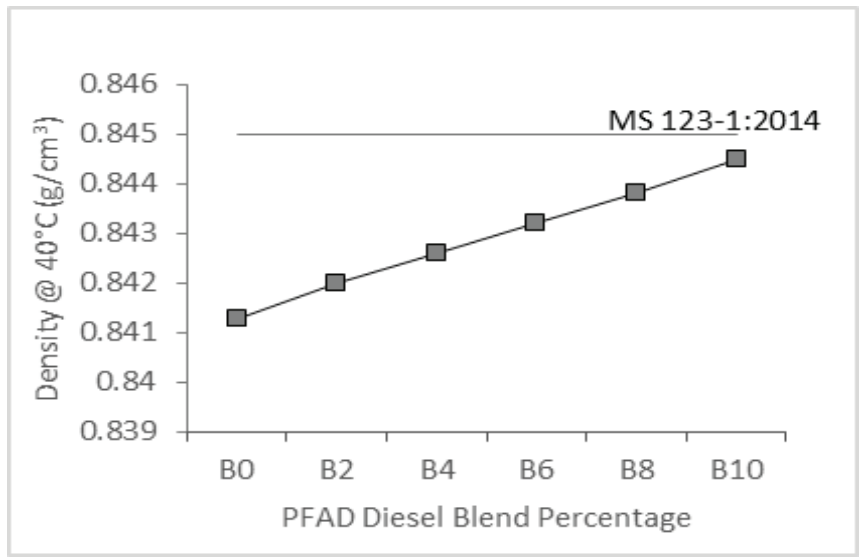

Fig. 2. Graph - Density of PFAD: Diesel Ratio

Figure 2 shows the density of diesel and PFAD blends obtained at $40{ }^{\circ} \mathrm{C}$. It has been found that $100 \%$ of diesel shows the lowest value of density. The value of density increases with the increment of the percentage of PFAD blend into the diesel mixture. The value of density still within the MS123:2014 Malaysian Standard for petroleum diesel even though the PFAD in the blend contain up to the $10 \%$ (B10).

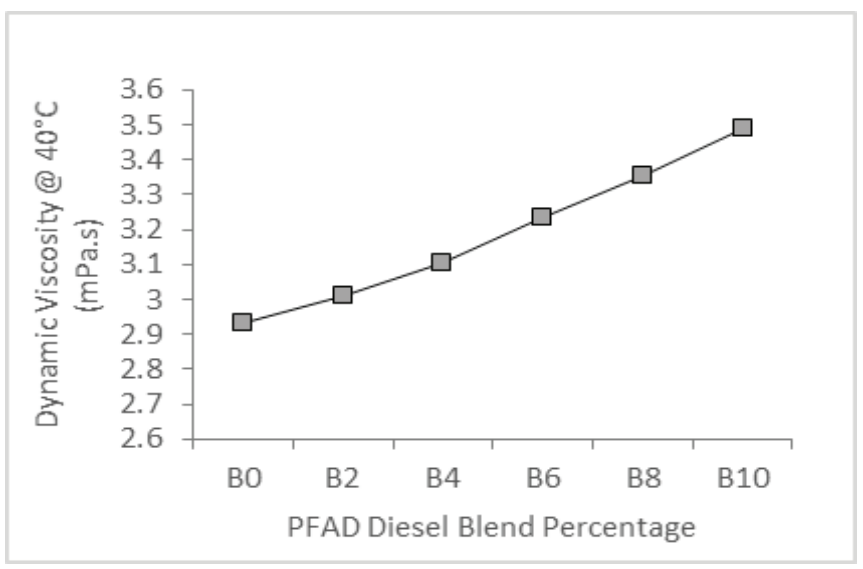

Fig. 3. Graph Dynamic viscosity of PFAD: Diesel Ratio

Figure 3 shows the dynamic viscosity of diesel and PFAD blends at $40{ }^{\circ} \mathrm{C}$. The results indicate that at a lower percentage of PFAD blend will result in lower dynamic viscosity and vice versa. At diesel and PFAD mixture up to $10 \%$ (B10), the dynamic viscosity increase $19 \%$ from the dynamic viscosity of diesel (B0). 


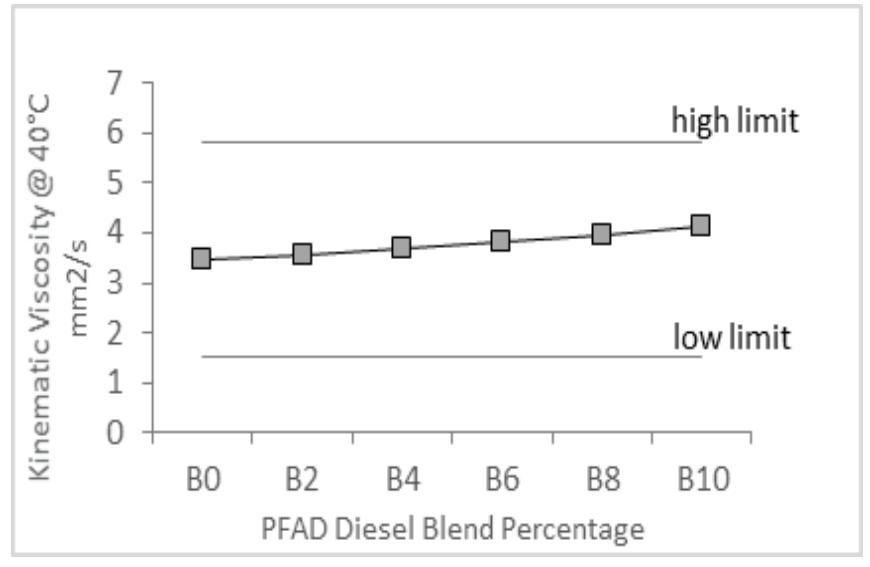

Fig. 4. Graph - Kinematic viscosity of PFAD: Diesel Ratio

Figure 4 shows the kinematic viscosity of the mixture tested at $40{ }^{\circ} \mathrm{C}$. The result shows that the increment of kinematic viscosity of the mixture is up to $18.5 \%$ with the increment of the percentage of diesel and PFAD blend in the mixture. However, the increments of kinematic viscosity are within the high and low limits (acceptable range limit) as described in MS123:2014.

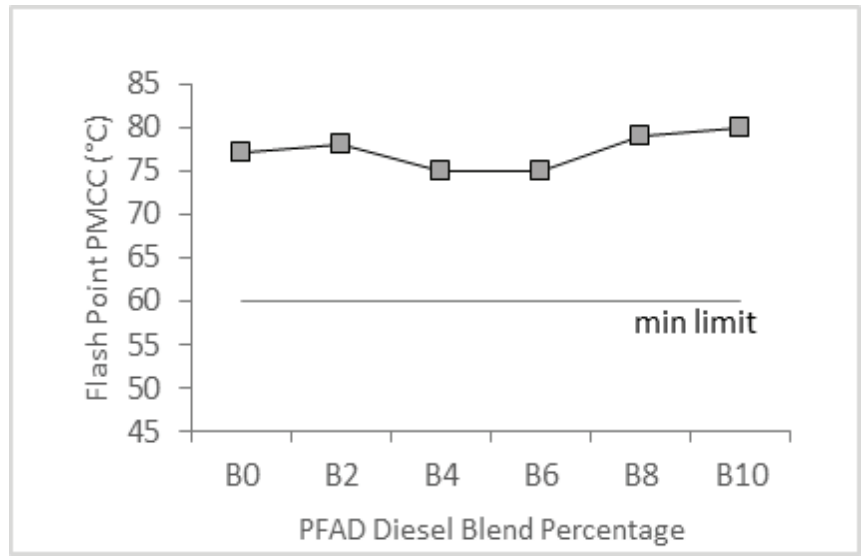

Fig. 5. Flash Point PMCC of PFAD: Diesel Ratio

The results of the flash point for diesel and PFAD blend are shown in Figure 5. In comparison with a standard value, the minimum flash point is $60^{\circ} \mathrm{C}$. It is showed that the values of the flash point for diesel and PFAD blend are within $75^{\circ} \mathrm{C}$ to $80^{\circ} \mathrm{C}$ which is $25 \%$ to $33 \%$ higher than the standard value. Thus, the flash point for all the diesel and PFAD blends within the acceptable value prescribed in the Malaysian Standard for Diesel, MS123:2014. 


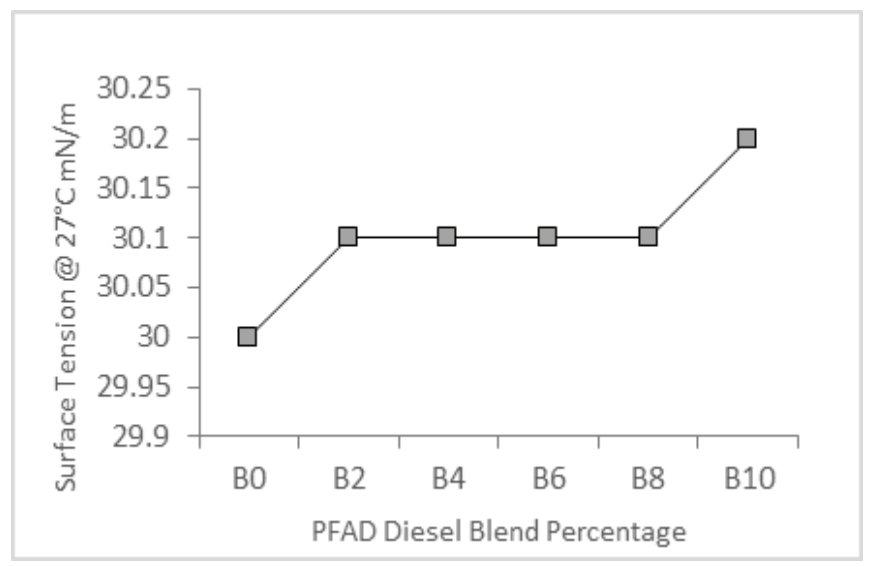

Fig. 6. Graph - Surface Tension of PFAD: Diesel Ratio

Figure 6 shows the surface tension of all diesel and PFAD blends. The surface tension of the blend was tested at $27^{\circ} \mathrm{C}$ which is around the ambient temperature. The values of all the blends differ by the range of $0.30 \%$ to $0.67 \%$ with respect to diesel (B0). Thus, it can be said that the surface tension of the blends did not have a much different with the diesel fuel.

\section{Conclusion}

Instead of palm methyl ester and envodiesel, Palm Fatty Acid Distillate is an alternative option for palm oil-based biofuel. By comparing PFAD with RBD palm oil, olein, and stearin, PFAD is the cheapest cost, making it suitable as a feedstock for fuel. The five diesel and PFAD blends (B2, B4, B6, B8 and B10) physical properties have been successfully measured. It is found that all the value for density, kinematics, viscosity and flash point were within the acceptable value of MS123:2014. The surface tension of the blends differ slightly (less than 1\%) compared to the diesel fuel.

\section{Acknowledgment}

The authors would like to extend their deepest gratitude to Universiti Tun Hussein Onn Malaysia for awarding research grant to undertake this research (STG U145, STG 1307 and MDR 1321). 


\section{References}

1) A.V. Metre, K. Nath Super Phosphoric Acid Catalyzed Esterification of Palm Fatty Acid Distillate for Biodiesel Production: Physicochemical Parameters and Kinetics. Polish Journal of Chemical Technology, 17(1): p. 88-96 (2015).

2) K.Y. Cheah, T.S. Toh, P.M. Koh, Palm Fatty Acid Distillate Biodiesel : Next Generation Palm Biodiesel. Paper Presented at Palm and Lauric Oil Conference \& Exhibition Price Outlook (POC), Kuala Lumpur, Malaysia, March 8-10 (2010).

3) S. Chongkhong, C. Tongurai, P. Chetpattananondh, Biodiesel Production by Esterification of Palm Fatty Acid Distillate.Biomass and Bioenergy, 31(8): p. 563568 (2007).

4) S. Chongkhong, C. Tongurai, P. Chetpattananondh, Continuos Esterification for Biodiesel Production from Palm Fatty Acid Distillate Using Economical Process. Renewable Energy, 34, p.1059-1063 (2009).

5) A. Hamim, Palm oil biodiesel programme to cover all of Malaysia by July, in The Star, Star Media Group Berhad: Kuala Lumpur (2014).

6) K. Krisnangkura, R. Simamaharnnop, Continuous transmethylation of palm oil in an organic solvent. Journal of the American Oil Chemists' Society, 69(2): p. 166169 (1992).

7) MPOB. Overview of the Malaysian Oil Palm Industry 1999-2015.

8) M.H.A.R. Mantari, M.N.M. Jaafar, Performance of Oil Burner System Utilizing Various Palm Biodiesel Blends, International Journal of Mechanical and Materials Engineering (IJMME). Vol. 4 (3), 273-278 (2009).

9) B.T.Y Ping, M. Yusof, Characteristics and properties of fatty acid distillates from palm oil. Oil Palm Bulletin, 59: p. 5-11 (2009). 